TM-1549

\title{
Report on Full-Scale Horizontal Cable Tray Fire Tests FY 1988
}

\author{
William M. Riches \\ Fermi National Accelerator Laboratory \\ P.O. Box 500, Batavia, Illinois
}

September 1988 


\section{Elermilab}

$T M-1549$

Report on

Full Scale Horizontal Cable Tray Fire Tests

FY 1988

William M. Riches

Fermi National Accelerator Laboratory

P.O. Box 500, Batavia, Illinois

September 1988 
TM-1549

William M. Riches

September 1988

\author{
REPORT ON \\ FULL SCALE HORIZONTAL CABLE TRAY FIRE TESTS \\ FY 1988
}

\title{
Abstract
}

In recent years, there has been much discussion throughout industry and various governmental and fire protection agencies relative to the flammability and fire propagation characteristics of electrical cables in open cable trays. It has been acknowledged that under actual fire conditions, in the presence of other combustibles, electrical cable insulation can contribute to combustible fire loading and toxicity of smoke generation. Considerable research has been conducted on vertical cable tray fire propagation, mostly under small scale laboratory conditions.

In July 1987, the Fermi National Accelerator Laboratory initiated a program of full scale, horizontal cable tray fire tests, in the absence of other building combustible loading, to determine the flammability and rate of horizontal fire propagation in cable tray configurations and cable mixes typical of those existing in underground tunnel enclosures and support buildings at the Laboratory. The series of tests addressed the effects of ventilation rates and cable tray fill, fire fighting techniques, and effectiveness and value of automatic sprinklers, smoke detection and cable coating fire barriers in detecting, controlling or extinguishing a cable tray fire. This report includes a description of the serles of fire tests completed in June 1988, as well as conclusions reached from the test results.

\section{Site Description}

Fermi National Accelerator Laboratory (Fermilab) is operated by Universities Research Association, Inc., a consortium of 56 major research-oriented universities, under contract with the Department of Energy. The Laboratory is located on 6800 acres at Batavia, Illinois. Its mission is to maintain, update and operate a high energy accelerator for the pursuit by physicists of elementary particle research.

Proton particles are accelerated through a $500 \mathrm{ft}$. long Linac, a $1500 \mathrm{ft}$. circumference Booster and a 4 mile circumference Main Ring to energies approaching one trillion electron volts ( $\mathrm{TeV})$. In addition to proton/antiproton colliding beam experiments in the Main Ring, the one $\mathrm{TeV}$ proton beam is extracted from the Main Ring and directed to a Switchyard where it is divided into separate beams supplying each of the Meson, Neutrino and Proton experimental areas where fixed target particle research experiments are conducted. The many miles of accelerator and beamline underground concrete tunnel enclosures contain beam pipe, electromagnets, water cooled electrical bus, cooling water piping and electrical power, signal and control cables installed in horizontal single and multiple stacked cable trays. Power 
supplies and electronic control equipment are located in adjacent above ground support buildings and are connected to the tunnel equipment through sealed vertical pipe penetrations. Large, high-bay experiment halls located at the ends of the various beamlines, a mile or more upstream from the switchyard, house large particle detector equipment and are connected by sealed horizontal pipe penetrations to adjacent electronic counting houses.

In addition to the accelerator and beamline enclosures, the Antiproton Ring and Transport Line represents another two-thirds of a mile of underground enclosures containing equipment similar to that in the accelerator enclosures. This facility accumulates and injects antiproton particles into the Main Ring for proton/antiproton colliding beam experiments.

\section{Fire Protection}

Above ground experimental halls, support buildings and counting houses are protected with a combination of automatic sprinklers, Halon 1301 suppression systems, smoke detection, heat detection, portable fire extinguishers, hose cablnets and exterior fire hydrants, as appropriate. However, because of the noncombustible construction and mainly noncombustible contents in the underground enclosures, together with their enormous lengths, fire suppression systems are not provided in the underground enclosures. Because of radiation levels experienced in some portions of the enclosures, fonization or photoelectric smoke detectors are not practical or functional. The 24 hour/day on-site Fermilab Fire Department provides a four minute response time to all accelerator and beamline locations upon fire alarm notification via a site-wide supervisory alarm system.

\section{Cable Tray Fire Test Program}

In cognizance that, although the accelerator and beamline enclosures were of noncombustible construction and that their contents were mainly noncombustible, ignition could occur due to an overheated magnet melting its coil insulation or due to an electrical short in the electrical cable trays, Fermilab initiated a full scale fire test program in July 1987 to determine the hazard presented by the horizontal cable trays. It was important to measure the flammability of the cables and the rate and length of fire propagation in the horizontal trays. It was also important to determine the need, value and cost-effectiveness of an automatic spriniler system throughout the enclosures as well as establishing that existing manual fire fighting plans and techniques were appropriate.

To this end, the Laboratory conducted a physical survey of accelerator and beamline enclosures to establish typical cable tray configurations and cable contents including quantities and types of cables and their insulation. This survey resulted in a plan to conduct a total of five burn tests, complete with thermocouple instrumentation, videotape and photography documentation, fire fighter observations and qualitative smoke analysis. Because of information gathered in the early tests, the program was expended to fourteen burn tests as described later in this report. 


\section{Cable Tray Fire Test Facility}

The fire test facility was constructed at grade level utilizing $10 \mathrm{ft}$. long by $12 \mathrm{ft}$. diameter precast concrete Main Ring enclosure sections set on a concrete slab to form a $65 \mathrm{ft}$. Iong tunnel, exactly duplicating the Main Ring. Each end was enclosed with a plywood wall and door. Varlable volume fans were installed in a wall opening at the upstream end with inside horizontal plywood directional baffles to provide laminar air flow through the tunnel; adjustable louvers discharging into a smoke chimney were installed in the downstream wall. Floor standing fans were also used to assist in controling air velocity and laminar air flow. Since several of the early tests were conducted during winter weather, electric and propane heaters were used to maintain tunnel temperatures.

Single, double or multiple stacked, $24 \mathrm{ft}$. long cable trays with various cable quantities and mixes were supported on unistrut along one wall near the center of the tunnel. An adjustable volume 20-40 KW, 12 inch diameter propane burner with a gravel diffuser was placed 6 inches below the cable tray to be burned. A total of 30 thermocouples were surface mounted and embedded in the cable bundles and connected to a data logger located in a van outside the tunnel. Thermocouple temperatures were recorded every 60 seconds during the course of the burn tests.

Pre-burn and post-burn photographs and a videotape camera inside the tunnel during each burn provided documentation and videotape recordings for each test. Fire Department observers with air packs and radio communication were located inside the tunnel during each test. Qualitative smoke monitoring equipment was installed at the exhaust louvers and chimney at the downstream end of the test enclosure.

An open-burning permit was obtained from the State of Illinols Environmental Protection Agency prior to the start of the test series. Burn residue was sampled and tested and disposed of as hazardous waste, where required. A11 tests were observed by representatives of the Department of Energy.

\section{Summary of Cable Tray Fire Tests}

Test No. 1 Main Ring

(1) 12 inch and (1) 9 inch cable tray, side by side, containing 193 control and signal cables; propane burner ignition for 11.5 minutes; flames self-extinguished 24 minutes after burner turned off; flame propagation $2 \mathrm{ft}$. upstream and $2.5 \mathrm{ft}$. downstream from burner.

Test No. 2, Booster Tunnel

(1) 12 inch and (3) 9 inch cable trays stacked 4 high, containing 188 power, control and signal cables; propane burner ignition for 60 minutes; flames self-extinguished within 2 minutes after burner turned off; flame propagation $2 \mathrm{ft}$. upstream and downstream from burner. 
Test No. 3, NMO Enclosure

(1) 18 inch cable tray containing (20) $500 \mathrm{MCM}$ power cables - $5 \mathrm{ft}$. cable floor; (1) 12 inch cable tray containing 57 control and signal cables - $6 \mathrm{ft}$. above floor; propane burner ignition for 7 minutes; no flame propagation of cables in lower tray; the 20 Hardline foam coaxial cables in the top tray exploded and propagated flame horizontally $7 \mathrm{ft}$. upstream downstream, very slowly ( 1.7 inches/minute) until it reached the end of the Hardline cable and extinguished.

Test No. 3A, Hardline Coaxial Cables Only

(1) 12 inch cable tray containing 20 polyethylene foam Hardline cables and 20 fused disk Hardline cables; propane burner ignition for 6 minutes; cable explosions began after 2 minute, 21 seconds of burn time; very slow horizontal flame propagation ( 1.7 inches/minute) both upstream and downstream until extinguished by fireman after 56 minutes of burn time.

Test No. 3B, Fused Disk Hardline Cables Only

(1) 12 inch cable tray containing only 20 fused disk Hardline coaxial cables; same results as observed in Test No. $3 \mathrm{~A}$.

Test No. 3C, Hardline Cables with Fire Resistant Cable Coatings

Duplication of Test No. 3A but 2 lineal feet of intumescent paint cable coating 4 feet downstream, and 2 lineal feet of non-intumescent fire resistant cable coating 4 feet upstream from the propane burner - each cable individually coated. The downstream intumescent paint coating was very effective in self-extinguishing the flames; however, the flames traveled through the non-intumescent coating upstream and continued to the end of the cables.

Test No. 3D, Hardline Cables with Fire Resistant Cable Coatings

(1) 6 inch cable tray containing 6 polyethylene foam Hardline cables and 6 fused disk Hardline cables each $10 \mathrm{ft}$. long cable was coated for 3 lineal feet at the upstream end with intumescent paint cable coating and for 3 lineal feet at downstream end with non-intumescent fire resistant cable coating. In this test, both coatings were effective in self-extinguishing the flaming polyethylene outer cable jacket after flame penetration of $1^{n}-2^{n}$ into the coating.

Test No. 3E, NMO Enclosure with Intumescent Cable Coating

Similar to Test No. 3: (1) 12 inch cable tray containing 53 control and signal cables, including 20 polyethylene foam Hardline coaxial cables. Two Iineal feet of intumescent paint cable coating fire barrier downstream, was applied to the total cable bundle as would be possible in the field; upstream, two vertical bundles of 10 Hardline cables each, vertically exiting from the horizontal tray, were coated with intumescent paint for a distance of 30 inches from 2 feet above the horizontal tray. The intumescent coating proved to be a very effective fire barrier for both the horizontal and vertical cable tray configurations. 
Test No. 4, New Muon Lab NMS

(3) 12 inch vertically stacked cable trays with 18 inch separation, contalning 235 and 135 flat planar single cables, and 124 miscellaneous ribbon, paired, multi-conductor and coaxial control and signal cables; propane burner ignition for 67 minutes; flames Immediately self-extinguished when burner was turned off; total flame propagation was 2 lineal feet on underside only of bottom tray.

Test No. 4A, New Muon Lab NMS

Same cable tray configuration and contents as Test No. $4 ;$ a $4 \mathrm{sq}$. ft. oll soaked cotton cloth 1 gnited on top of the 135 planar cables in the middle tray; ignition of cables in top tray; all flames self-extinguished after 12 minutes; extent of flame propagation was one foot on surface of cables in middle tray and 2 feet on the underside of cables in top tray.

Test No. 4B, New Muon Lab NMS

Same cable tray configuration and contents as Test No. 4 but with 30 flat planar cables loosely draped between the 3 trays and open air space provided in the trays to permit air movement and flame propagation between trays; propane burner Ignition for 40 minutes; immediate self-extinguishment of flames when burner was turned off; extent of burn was 2 lineal feet underneath the bottom tray and moderate melting and charring of loosely draped cables between the bottom and middle trays for a distance of one foot above the bottom tray.

Test No. 4C, New Muon Lab NMS

Same cable tray configuration and contents as Test No. 4 but with 30 flat planar cables, in two tightly compacted bundles, draped between the 3 trays and open air space provided in the trays to permit air movement and flame propagation between trays; propane burner ignition for 30 minutes; flames Immediately self-extinguished when burner was turned off; extent of burn was 2 Ineal feet underneath the bottom tray and moderate melting and charring of the draped cables between the bottom and middle trays for a distance of 6 inches above the bottom tray.

Test No. 4D, New Muon Lab NMS

Same cable tray configuration and contents as Test No. 4 but with 30 flat planar cables, at the extreme upstream end of the cable trays, loosely draped and hanging from all three trays down into the propane bumer; propane burner ignition at $20 \mathrm{KW}$ for 4 minutes and at $40 \mathrm{KW}$ for an additional 5 minutes; flames immediately self-extinguished when burner was turned off. The flat planar cables did not propagate flames either vertically or horizontally. All cable damage and pyrolization was the result of the flames from the propane burner. 
Test No. 5, CDF Moveable Cableway

(1) 18 inch wide by $10 \mathrm{ft}$. long, open bottom cable tray with 5 inch metal side extensions and a metal cover, containing 35 multi-conductor cables, 500 RG 58 $\mathrm{C} / \mathrm{U}$ coaxlal cables, 100 twinax cables and 52 flat ribbon cables in the four tightly compacted groupings; propane burner ignition for 31 minutes at $20 \mathrm{~kW}$ and for an additional 15 minutes at $40 \mathrm{~kW}$; flame propagation $2 \mathrm{ft}$. upstream and downstream during an 84 minute period with flame self-extinguishment, but followed by deep-seated pyrolization downstream and slow propagation to the end of the cables $5 \mathrm{ft}$. downstream, 171 minutes after original burner ignition; downstream deep-seated fire extinguished by fireman using a portable Halon extinguisher.

Detalled descriptions of each fire test, including sketches of cable tray configuration and cable contents, instrumentation, ventilation rates, Fire Department observations, photographs and graphs of thermocouple temperatures are available in a complete test report at Fermilab. Videotape recordings have been edited to illustrate the highlights of each test.

\section{Discussion of Fire Test Results}

1. Since the main purpose of this series of cable tray fire tests was to determine the flammability of cable insulation, rate of horizontal flame propagation and possible benefit of automatic fire suppression systems in typical Fermilab underground enclosures, no effort was made to measure the probability or ease of ignition of the cables. With no other combustibles present, it was assumed that ignition could occur due to an overheated magnet or an electrical short circuit in the cable tray. To this end, every effort was made to ignite the cable insulation including increasing the propane burner intensity from $20 \mathrm{KW}$ to $40 \mathrm{KW}$ and extending the burner ignition time to more than 60 minutes during some tests. These tests, therefore, represented "worst case" conditions. In actual field conditions, it is highly unlikely that any probable ignition source would be sustained for the duration of time utilized in the tests. For the same reasons, smoke generation during the tests represented "worst casen $^{n}$ conditions.

2. Ignition of the larger sized power cables could not be achieved during any of the tests. PVC insulated cables self-extinguished with a minimum of flame propagation. Twist' $n$ ' flat planar cables would not support combustion. Only the polyethylene insulated Hardline coaxial cables (Test No. 3 series) and the polyethylene insulated flat ribbon cable (Test No. 5) supported horizontal flame propagation with accompanying dripping of flaming insulation, but at an extremely slow propagation rate. After 2.5-3 minutes of burner ignition to the Hardine cables, the out-gassing pressure buildups inside the cable ruptured the aluminum casing causing a minor explosion, fireball and heavy smoke generation. The subsequent horizontal flame propagation along the outer polyethylene jacket was of low intensity with only light smoke generation. The intumescent paint cable coating, applied to the total cable bundle, after the cables were placed in the tray, proved to be a very effective fire barrier for both horizontal and vertical Hardline cable runs. 
Although cables were placed in the trays in a rather random fashion with loose compaction as would be found in the field, it became apparent during the fire test series that resistance to ignition and flame propagation increased with greater cable densities and compaction.

3. Thermocouple temperatures, both surface mounted and imbedded in the cable bundles, were recorded during the fire tests. As Indicated by the graphs included with the Individual test reports, due to the low heat release rate and very slow flame propagation rate, automatic sprinklers if installed in the enclosures would be very slow to operate, if indeed they even operated. The very slow temperature rise of the imbedded thermocouples would indicate that linear heat detection installed in the cable trays might not be dependable or practical since there is every probability that they would become buried as additional cables were added to the trays.

4. Observations by Fermilab Fire Department personnel located in the fire test tunnel during each test indicated no problem in heat buildup, no appreciable increase in flame propagation as a result of increased ventilation rates, and no serious visibility problems. Any flame propagation was very slow and easily contained by portable fire extinguishers. The greatest surprise was the violence of the short-lived Hardine cable explosions, but once finished, there was no problem in fire containment or extinguishment. The deep seated fire and re-ignition in Test No. 5 was also a surprise to the Fire Department but represented no problem in containment or extinguishment due to its very slow propagation. Early detection was proven to be of much greater importance than the presence of automatic suppression systems.

\section{Conclusions}

1. High intensity fires with fast flame propagation by cable installations in Fermilab underground enclosures is highly improbable, if not impossible. Adequate sealing of penetrations to above ground support facilities is a necessity.

2. Automatic sprinkler systems in Fermilab underground enclosures would be of little benefit and would not be cost-effective due to the low heat release rate and very slow flame propagation, if any, in horizontal cable trays. Automatic sprinkler systems would be ineffective in minimizing potential smoke damage.

3. Early warning fire detection followed by manual fire fighting is the most effective defense against underground enclosure fires. Fire detection might be accomplished in some cases by accelerator malfunction or by an appropriate and functional state-of-the-art smoke detection system. Linear type heat sensors in cable trays are not recommended. 
4. In the Main Ring, Booster and New Muon Lab NMS fire tests, the cable tray fire self-extinguished almost immediately or within a few minutes after removal of the propane burner ignition source. Because of machine safety interlocks and time required for access into the enclosures, it is probable that a fire would have self-extinguished before the arrival of fire fighters. Therefore, it is somewhat questionable whether automatic smoke detection systems would be justified in such areas.

5. Hardline coaxial cables are essentially signal and communication links, not directly associated with accelerator operation. In quantities to provide sufficient fuel loading and with ample oxygen supply, they do support horizontal flame propagation at a very slow rate of 1.7 inches/minute, which could go undetected for a considerable period of time. In such cases, a very early warning smoke detection system might be appropriate. An alternative could be the fleld application to cable bundles, of intumescent type cable coating at selected intervals to serve as a fire barrier and limit the extent of flame propagation. This proved to be very effective for both horizontal and vertical Hardline cable runs.

6. The presence of an automatic sprinkler or fire detection system would not prevent a cable tray fire but rather would only limit the time for possible slow flame propagation before extinguishment. Property loss value would not be a major factor. Accelerator or experimental beam time would be lost in any case, with an estimated one person-week recovery time. During an operating period, such an outage would undoubtedly be also used to accomplish desired elective maintenance and development work.

7. Automatic sprinkler spray nozzles mounted along each side of the Collider Detector Facility movable cableway would not be thermally activated in the event of a cable fire even if equipped with heat reflectors. They would be ineffective against a deep-seated cable fire. The existing VESDA smoke detection system provides very early warning to the on-site Fire Department. Flame propagation would be extremely slow and with a very low heat release rate. Portable halon extinguishment was proven to be most effective.

8. Existing Fermilab Fire Department response planning and fire fighting techniques were evaluated with the data from the cable tray fire test series and judged to be sound. Portable fire extinguishers are most effective for cable tray fires. Increased ventilation rates have little impact on horlzontal flame propagation rates. Visibility is not a problem in ventilated tunnels even at an air velocity of as little as 20-50 fpm. However, smoke ejection equipment should be avallable for use in enclosures with little ventilation. 


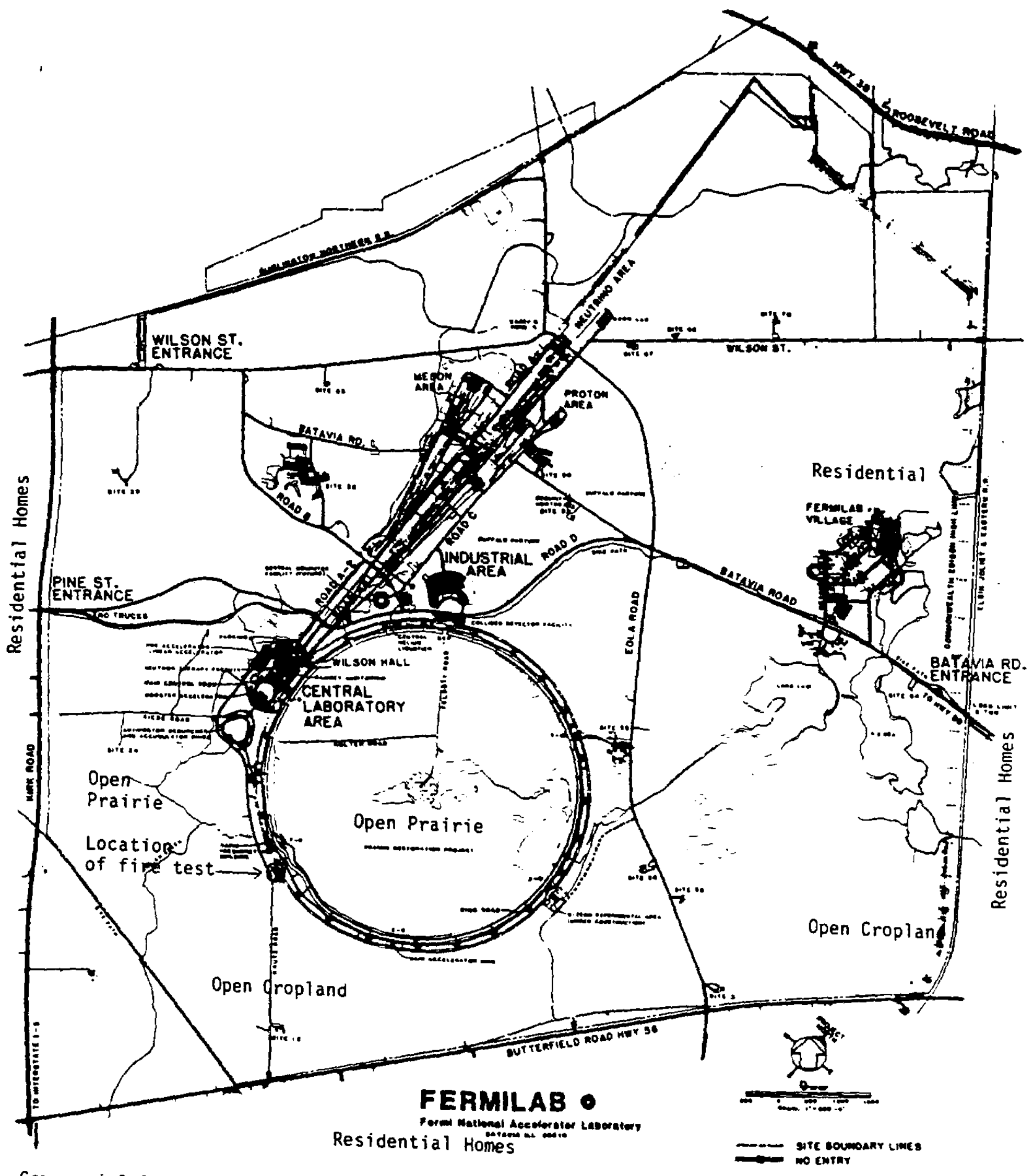

Commercial Buildings

Exhibit 1. Site Layout. 